\title{
Phylogenetic evidence for a Miocene origin of Mediterranean lineages: species diversity, reproductive traits and geographical isolation
}

\author{
P. Vargas ${ }^{1}$ (D) M. Fernández-Mazuecos ${ }^{1}$ (D) \& R. Heleno ${ }^{2}$ \\ 1 Real Jardín Botánico de Madrid (RJB-CSIC), Madrid, Spain \\ 2 Centre for Functional Ecology, Department of Life Sciences, University of Coimbra, Coimbra, Portugal
}

\section{Keywords}

Angiosperm evolution; clade divergence;

Mediterranean climate; Mediterranean floristic region (MFR); phylogeny; pre-Pliocene.

\section{Correspondence}

P. Vargas, Real Jardín Botánico de Madrid (RJB-CSIC), Plaza de Murillo 2, 28014 Madrid, Spain.

E-mail: vargas@rjb.csic.es

\section{Editor}

J. Thompson

Received: 5 June 2017; Accepted: 30 August 2017

doi:10.1111/plb.12626

\section{ABSTRACT}

- A review of 27 angiosperm clades (26 genera) of species-rich and species-poor plant groups of the Mediterranean floristic region was performed with phylogenetic and biological trait data.

- The emergent pattern is that a majority of Mediterranean plant clades split from their sister groups between the Miocene (23-5 Ma) and the Oligocene (34-23 Ma), far earlier than the onset of the Mediterranean climate (ca. 3.2 Ma). In addition, 12 of 14 clades of the species-poor group have stem ages inferred for each clade in the Miocene or older, and six of 13 clades within the species-rich group show divergence of each stem clade within the Oligocene and/or Miocene.

- High levels of species diversity are related to an ancient (Paleocene-Miocene) origin and also to recent origin (Pliocene-Pleistocene) followed by active speciation and even explosive radiations: some species and lineages diversified over a short period (Aquilegia, Cistus, Dianthus, Linaria sect. Supinae, Reseda). In the species-rich group, key reproductive characters were found to be significantly more important for species recognition than key vegetative characters in eight clades, but no difference was found in four clades, and vegetative characters were predominant in one clade (Saxifraga). Geographical differentiation is proposed as predominant over divergence driven by pollination ecology.

- We hypothesise an evolutionary process in which lineages adapted to pre-Mediterranean (pre-Pliocene) conditions in relatively small, xeric areas became strongly competitive and expanded as the Mediterranean climate became dominant (PlioceneQuaternary) across the Mediterranean Basin.

\section{INTRODUCTION}

The single figure published in On the Origin of Species illustrates the hypothetical patterns of evolution as envisioned by Darwin (1859). Four main representations were proposed for the evolution of species from common ancestors: extinction, stasis with low rates of speciation despite ancient origin, moderate diversification and high levels of diversification (Fig. 1). To the best of our knowledge, this evolutionary scheme of time of differentiation has not been tested for any flora of a large territory. Available phylogenies from a considerable number of plant clades provide the opportunity to reconstruct evolutionary patterns for a high number of taxa in a large territory such as the Mediterranean floristic region (MFR; Forest et al. 2007; Fiz \& Valcárcel 2013; Mishler et al. 2014).

The Mediterranean Basin is a biodiversity hotspot of species and endemism (Mittermeier et al. 2004; Médail \& Diadema 2009). Around 25,000 species of angiosperms have been estimated for the MFR, which are primarily circumscribed within a few unrelated families (Asteraceae, Brassicaceae, Poaceae, Lamiaceae, Caryophyllaceae, Cistaceae, among others;
Euro+Med PlantBase 2006). Low representation of ancient tropical lineages is interpreted as a result of four major waves of extinction associated with rapid climate change over the last 15 million years (Barrón et al. 2010). Only one angiosperm family (Drosophyllaceae) is endemic to the MFR, in contrast to higher numbers of families in the other four Mediterraneantype biomes, which suggests failure in long-term isolation and survival of ancient lineages (Valente \& Vargas 2013). Paleobotanical and phylogenetic data reveal that the floras of Mediterranean-type ecosystems are predominantly formed by relatively recent plant speciation (Rundel et al. 2016). Indeed, it has been postulated that recent immigration of plant lineages from Europe, Africa and Asia was followed by local differentiation to bring about current species diversity in the Mediterranean Basin. As a result, the ca. 160 families, over 1,000 genera and about 25,000 species that occur in the MFR illustrate angiosperm diversity and a great deal of vegetative and flower forms (Euro+Med PlantBase 2016).

Species recognition and diversity are linked to morphological variability of either vegetative or reproductive characters in any flora. Numerous Mediterranean species exhibit wide-open 


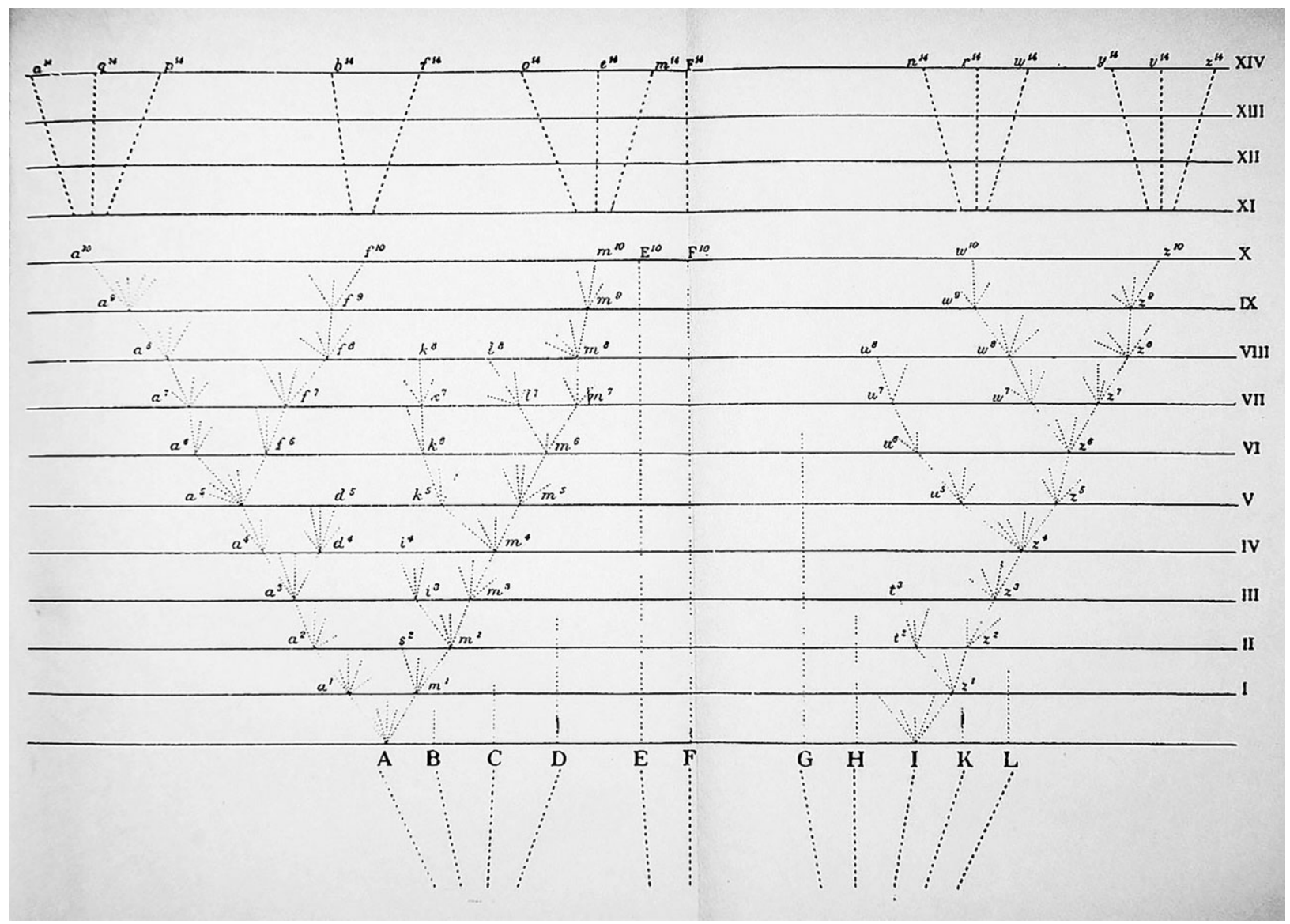

Fig. 1. Phylogenetic diagram proposed by Darwin (1859) that helped hypothesise the principles of natural selection and extinction. Each interval between horizontal lines represents a thousand generations. Species $\mathrm{A}$ represents a successful lineage (species-rich lineage) that generated eight species (A-M) at generation time XIV. Species I shows a moderate diversification (six species). In contrast, species F represents no diversification (evolutionary stasis), while species B, C, $D, E, G, H, K$ and $L$ represent extinction at different generation times.

flowers (e.g. Cistaceae, Rosaceae, Paeoniaceae) that allow pollination by a large variety of insects (allophilic flowers). Flower generalisation coexists with some of the most complex flower types in the angiosperms (e.g. Fabaceae, Orchidaceae, Plantaginaceae) that restrict access to floral rewards (euphilic flowers; Faegri \& van der Pijl 1979). For Darwin (1859), flower diversity of angiosperms could only be explained by accumulation of floral change over millions of years (Friedman 2009). However, it has been accepted in the last decades that the Mediterranean climate appeared relatively recently in the Pliocene (ca. $3.2 \mathrm{Ma}$ ) and established shortly after (last 2.8 million years; Suc 1984), although some authors have questioned this timing for the origin of the MFR (Rundel et al. 2016). Therefore, the question remains as to whether a predominant differentiation of angiosperms (active speciation) associated with change in reproductive (including flower traits) and vegetative characters has primarily been the result of ancient (pre-Pliocene) or recent (Pliocene, Quaternary) evolutionary events.

Time-calibrated phylogenetic trees provide a powerful tool for hypothesis testing of evolutionary patterns (Vargas \& Zardoya 2014). Divergence times of stem and crown nodes help estimate when traits related to Mediterranean conditions appeared in geological time. In early studies, genetic distance matrices were used to estimate substitution rates for molecular clock estimations, while these substitution rates are currently derived from phylogenies or from sequence data in conjunction with tree topologies (Rutschmann 2006). This approach, together with establishing calibration points (typically fossils), has been increasingly used for Mediterranean plants in the last two decades and used to describe general patterns of divergence across genera (Fiz \& Valcárcel 2013; Fernández-Mazuecos et al. 2014; Jiménez-Mejías et al. 2015). Although the proportion of studies including phylogenies is still relatively small when compared to the large diversity of the MFR, a significant number of them include a molecular-clock approach that has been used to set a time scale for the evolution of reproductive traits.

In this review, we test the hypothesis that the Mediterranean flora shows an evolutionary pattern where greater species diversity is associated with ancient divergence (Darwin 1859). In particular, this Darwinian hypothesis tries to find evidence for common evolutionary patterns related to differentiation times in such a way that ancient divergence resulted in considerable shifts of reproductive traits by accumulation of changes over time, whereas recent divergence is associated with subtle changes (Darwin 1859). In other words, the canon of 'Natura non facit saltum [nature does not make a leap]' (Darwin 1859) is herein explored using a spatio-temporal framework. The following specific questions are addressed: (i) is primarily the 
Mediterranean flora of recent origin as generally assumed (post-Pliocene) or does the considerable species diversity observed today correspond to an ancient divergence as implied by Darwin; (ii) what are the emergent evolutionary patterns for the net contribution of reproductive and vegetative characters to species diversity; and (iii) do reproductive (floral) and vegetative characters differ across Mediterranean plant clades that show pollinator specialisation?

\section{MATERIAL AND METHODS}

\section{Plant groups}

In order to explore patterns of plant diversity in the MFR, a wide range of differentiation levels (from high to low species diversity) across plant lineages were explored. We searched for evolutionary studies of plant clades that provided: (i) high or low numbers of species, particularly genera that show specialised features related to evolution under the summer drought conditions of the Mediterranean climate; (ii) a sample of the majority of species of each plant clade; and (iii) phylogenies including estimates of lineage divergence based on reliable time calibrations. Only assemblages of species forming monophyletic groups (typically genera) were considered as clades. A literature survey for representative examples that includes data on reproductive and vegetative traits was conducted. As a result, we chose 27 Mediterranean plant clades that were arranged into two categories: species-rich group (13 speciesrich clades; Fig. 2) and species-poor group (14 species-poor clades; Fig. 3, see Tables S1, S2). High diversification (speciesrich group) was assumed for clades including numerous species (typically more than ten) distributed in the MFR. In contrast, low diversification (species-poor group) refers to clades with few species, all or most of them distributed in the MFR. Representatives of the main families (Asteraceae, Poaceae, Apiaceae, Brassicaceae) of the MFR were included as well as model plants (Antirrhinum, Arabidopsis, Brachypodium) from Europe that have been intensively studied.

\section{Evolutionary patterns}

General descriptions of species numbers, plant distributions and centres of diversity were obtained from floristic, taxonomic and phylogenetic studies (Table S1). Evolutionary patterns were evaluated based on quantification of spatio-temporal processes in a phylogenetic framework.

The following data were obtained from the original publications.

a) Species number: Floristic and taxonomic studies do not usually agree with each other about recognition of species within a genus. For the sake of simplicity, data for species numbers were taken from Mabberley (1997) for the world and from Flora Europaea (Tutin et al. 1964-1980) for Mediterranean Europe. In addition, Euro+Med (2016) and specific taxonomic accounts were also consulted.

b) Distribution: Across the Mediterranean Basin and the world.

c) Biogeography: Centres of diversity and patterns of colonisation across the Mediterranean Basin based on species distributions and phylogenetic relationships.

d) Clade origin and differentiation: Temporal origin (geological periods) for each Mediterranean group is based on time-
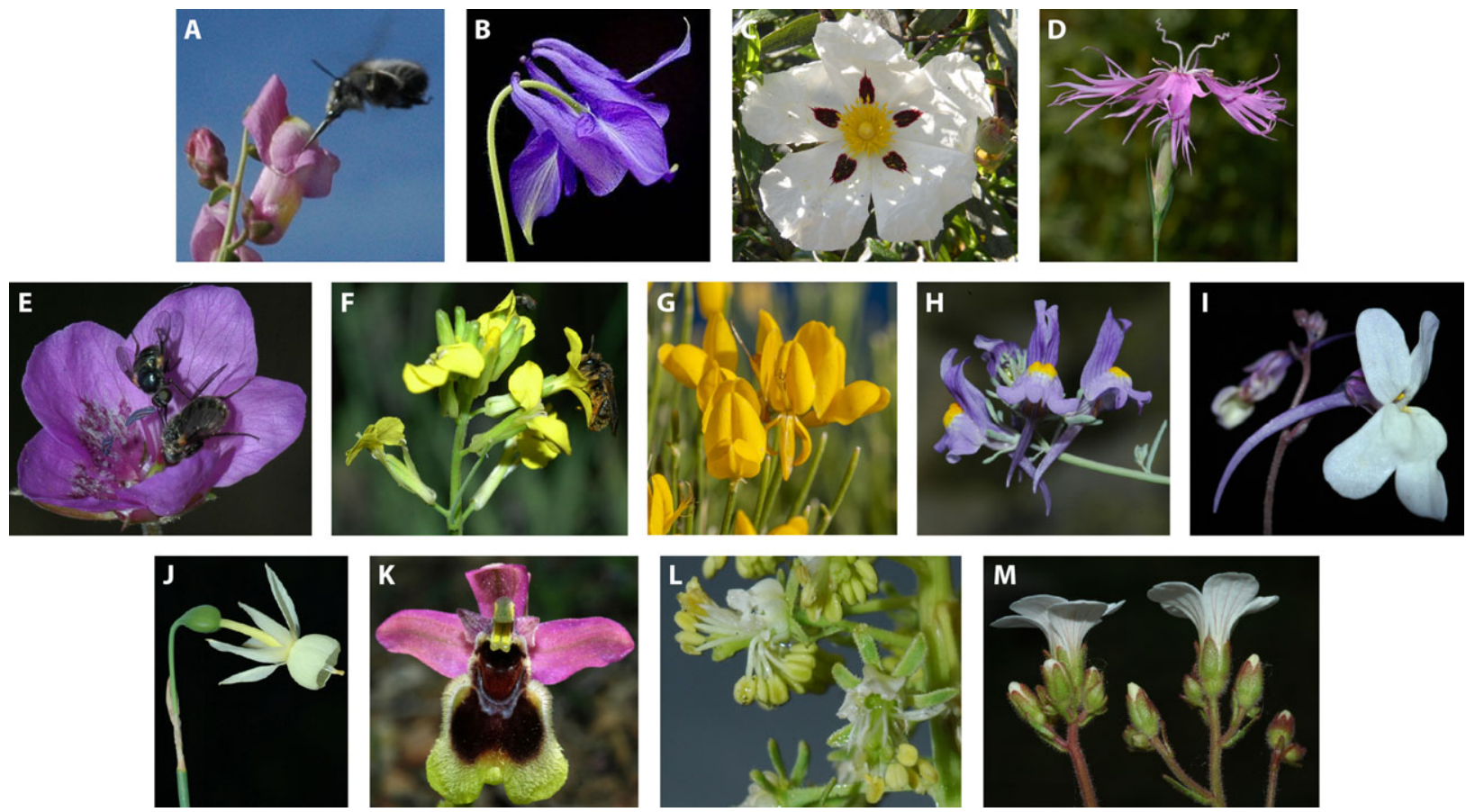

Fig. 2. Photographs of representative species of the species-rich group (13 clades) chosen in this review from previous studies of the Mediterranean floristic region (see text): A, Antirrhinum charidemi; B, Aquilegia vulgaris; C, Cistus ladanifer; D, Dianthus hyssopifolius; E, Erodium carvifolium; F, Erysimum merxmuelleri; G, Genista dorycnifolia; H, Linaria alpina; I, Linaria nigricans; J, Narcissus pallidulus; K, Ophrys tenthredinifera; L, Reseda phyteuma; M, Saxifraga granulata. Photographs by P. Vargas, except for G (Serapio). 

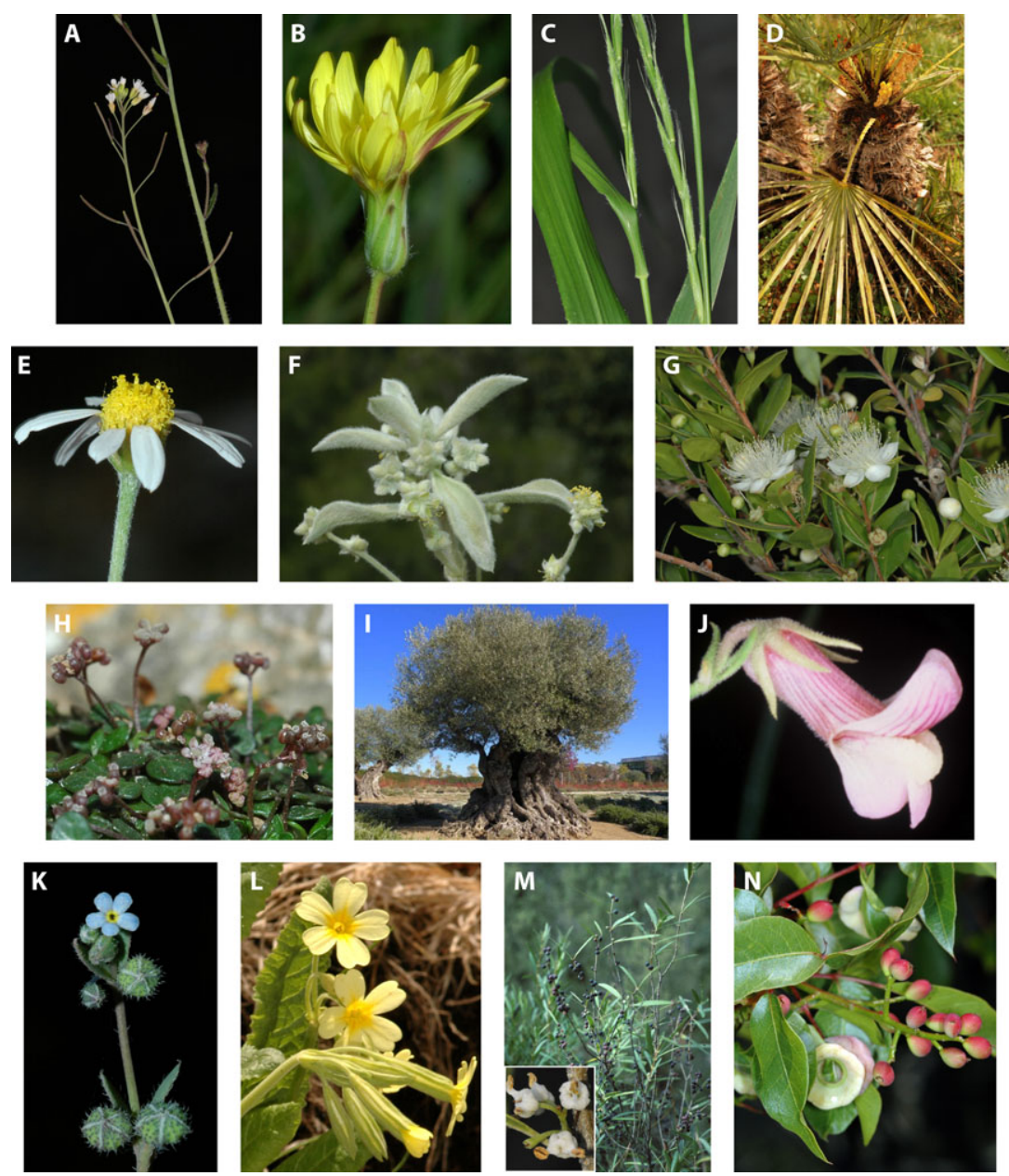

Fig. 3. Photographs of representative species of the species-poor group (14 clades) chosen in this review from previous studies of the Mediterranean floristic region (see text): A, Arabidopsis thaliana; B, Avellara fistulosa; C, Brachypodium sylvaticum; D, Chamaerops humilis; E, Castrilanthemum debeauxii; F, Mercurialis tomentosa; G, Myrtus communis; H, Naufraga balearica; I, Olea europaea; J, Pseudomisopates rivas-martinezii; K, Gyrocaryum oppositifolium; L, Primula veris; M, Phillyrea angustifolia; N, Pistacia terebinthus. Photographs by M. Luceño \& P. Vargas. calibrated phylogenies (Ronquist 2014). On the one hand, the origin of a particular clade was considered to have occurred in the estimated time of the split between the ingroup and its sister group (stem age), as previously discussed in a phylogenetic context (Donoghue et al. 2001; Vargas 2007; Fiz \& Valcárcel 2013). On the other hand, the origin of extant differentiation within each clade was recognised from the age of the most recent common ancestor (basal-most split) of the ingroup (crown age). Data were taken from original publications (Table S1).

e) Evolutionary patterns: Rates of differentiation within the ingroup are based on species numbers and divergence times. Net diversification rates ( $r$, measured as net speciation events per million years) were estimated using Magallón \& Sanderson's (2001) whole-clade method, as implemented in the $\mathrm{R}$ package geiger (Harmon et al. 2008). Calculations were conducted using the number of species and the mean estimated crown age of each clade (or mean estimated stem age in cases where the crown age was unavailable). Based on diversification rate values, each clade was classified into four categories: no diversification $(r=0)$, slow diversification $(0<r<0.1)$, medium diversification $(0.1<r<1)$ and fast diversification $(r>0.1)$.

f) Drivers of speciation: Factors historically associated with the observed differentiation and species recognition are typically geography, ecology, hybridisation and chromosome variation.

\section{Plant traits}

Biological characteristics (traits) of each plant clade were gathered and summarised as follows (Table S2):

a) Habit: Predominant growth form (annual herbs, perennial herbs, shrubs, trees).

b) Fruit type: Fleshy or dry fruits, seed abundance per fruit.

c) Self-compatibility: Inferred from predominant patterns - i.e. whether most of species tested are self-compatible (SC) or self-incompatible (SI) - in crossing experiments within each plant clade.

d) Sexual system: Hermaphroditic versus dioecious and other conditions.

e) Corolla shape: Occurrence of fused (gamopetaly) or free (choripetaly) petals.

f) Flower openness: Wide open and fully accessible (e.g. dish-shaped corollas of Cistaceae) or occluded and with limited accessibility (e.g. personate corollas of Antirrhinum) to pollinators.

g) Flower size: Measurements taken from Flora Europaea (Tutin et al. 1964-1980).

h) Pollinators: Data from the literature and personal observations by experts were used to determine predominant pollinator guilds (Table S2, column (h)). This approach was complemented by evaluation of pollination syndromes (i.e. suites of floral traits associated with a particular pollinator 
Table 1. Contingency analysis (G-test) of differences in proportions of reproductive and vegetative characters used in taxonomy of each genus of the 13-species-rich group.

\begin{tabular}{llllll}
\hline Genus & $\begin{array}{l}\text { Reproductive } \\
\text { taxonomic } \\
\text { characters }\end{array}$ & $\begin{array}{l}\text { Vegetative } \\
\text { taxonomic } \\
\text { characters }\end{array}$ & $G$ & df & $P$-value \\
\hline Antirrhinum & 18 & 15 & 0.273 & 1 & 0.6013 \\
Aquilegia & $\mathbf{2 6}$ & 14 & 3.656 & 1 & $0.0559 \sim^{*}$ \\
Cistus & 15 & 13 & 0.143 & 1 & 0.7053 \\
Dianthus & 78 & 60 & 2.355 & 1 & 0.1249 \\
Erodium & 25 & 26 & 0.020 & 1 & 0.8886 \\
Erysimum & $\mathbf{4 3}$ & 20 & 8.594 & 1 & $0.0034^{* *}$ \\
Genista & $\mathbf{1 3}$ & 5 & 3.683 & 1 & $0.0550 \sim^{*}$ \\
Linaria s & $\mathbf{5 6}$ & 27 & 10.35 & 1 & $0.0013^{* *}$ \\
$\quad$ Supinae & & & & & \\
Linaria s & $\mathbf{3 7}$ & 18 & 6.701 & 1 & $0.0096^{* *}$ \\
$\quad$ Versicolores & & & & & \\
Reseda & $\mathbf{1 8}$ & 8 & 3.947 & 1 & $0.0470^{*}$ \\
Saxifraga & 32 & $\mathbf{7 4}$ & 17.11 & 1 & $0.00004^{* * *}$ \\
Narcissus & $\mathbf{4 5}$ & 10 & 24.09 & 1 & $9.19^{*} 10^{-4 * * *}$ \\
Ophrys & $\mathbf{5 0}$ & 1 & 60.86 & 1 & $6.11^{*} 10^{-15 * * *}$ \\
\hline
\end{tabular}

The significance level of the observed differences are highlighted as:

$* * * P<0.001 ; * * P<0.01 ; * P<0.05 ; \sim * P \approx 0.05$.

Significant values in bold.

group that characterise groups of plant species) in order to assess additional species of the same clade.

\section{Vegetative and reproductive characters}

Individuals from different populations display some degree of morphological constancy, and also variability of several traits. Taxonomists have traditionally focused on this variability to score variation of traits as continuous and discontinuous, followed by identification of discrete morphological characters used to help describe and recognise species (Winston 1999). In particular, discrete characters from the two main plant parts (vegetative and reproductive traits) have been basically used by taxonomists to identify key character states across populations for species recognition (Stuessy 2008). Therefore, species recognition strongly depends upon identification of discontinuous reproductive (inflorescence, flower and fruit) and vegetative (roots, stems, branches, leaves) character states that help cluster together populations into species (Table S2). In contrast, populations showing a continuous range of morphological variability (spectral gradation) are considered to belong to a single polymorphic species. As a result, key character states are clear-cut traits that can be used in keys to species in taxonomic accounts and floras. We searched for key character states (taxonomic characters henceforth) from taxonomic keys to species from Flora Europaea (Tutin et al. 1964-1980) because taxonomic characters are considered to hold the most important features associated with species recognition (Winston 1999).

We determined the number of vegetative and reproductive characters used for species recognition in the taxonomy of each plant clade using taxonomic keys to species from previous studies (Tutin et al. 1964-1980). Each character state from each step of the taxonomic key was recorded as either a reproductive or vegetative character (many times both types of characters at the same step). We then evaluated if there were consistent differences in the number of vegetative and reproductive characters across plant clades using a Generalised Linear Mixed Model (GLMM), with trait type as a predictor, number of traits as a response variable with Poisson distributed errors, and clade as a random factor. Furthermore, we evaluated whether the proportion of vegetative and reproductive taxonomic characters within each genus differed significantly from a 1:1 ratio by implementing likelihood ratio tests (G-test). Finally, we used a Generalised Linear Model (GLM) to evaluate whether species-rich clades, either with pollination mostly by bees or with generalist insect pollination, differed in the ratio of reproductive and vegetative characters. The response was modelled according to a gamma distribution with an inverse link function and the residuals visually inspected. All tests were implemented in R 3.2.1 ( $\mathrm{R}$ Development Core Team 2015), using packages base and lme4.

\section{RESULTS}

The genera and plant groups formed monophyletic groups of species, except for Cistus and Dianthus. In those cases, particular monophyletic groups of species were considered as plant clades for further analyses: white-flowered Cistus plus Halimium umbellatum (Guzmán et al. 2009); Dianthus sections Leiopetali, Fimbriati, Dentati and Carthusiani (Valente et al. 2010).

\section{Divergence time estimates}

Estimated ages of splits between the 27 plant clades and their respective sister groups varied considerably, and pertained to the Cretaceous, Paleocene, Eocene, Oligocene, Miocene, Pliocene and Quaternary (Fig. 4). The oldest divergence times were found in two species-poor genera: Mercurialis (CretaceousPaleocene) and Myrtus (Eocene). In contrast, more recent divergence (Pliocene-Quaternary) was observed in both plant groups, although it was found in a higher number of clades of the species-rich group (Aquilegia, Cistus, Dianthus, Erysimum, Linaria sect. Supinae, Reseda sect. Phyteuma) than the speciespoor group (only Pseudomisopates). As a whole, nine (Antirrhinum, Avellara, Castrilanthemum, Erodium, Linaria sect. Versicolores, Olea europaea complex, Ophrys, Phillyrea, Saxifraga sect. Saxifraga) of the 27 plant clades show a high likelihood of divergence exclusively in the Miocene, while seven (Arabidopsis, Chamaerops, Genista sect. Spartocarpus, Narcissus, Naufraga, Pistacia, Primula sect. Primula) span two periods including the Miocene (Fig. 4).

\section{Geographical differentiation}

High numbers of species are found across the MFR. Although all the clades of this study are distributed across the Mediterranean Basin, a centre of species and lineage diversity is clearly found in the western Mediterranean for Antirrhinum (90\% species), Cistus (70\%), Linaria sect. Versicolores (90\%), Linaria sect. Supinae (70\%) and Narcissus (80\%; Table S1). Given that similar levels of diversity are found in the eastern Mediterranean for some other genera (Astragalus, Centaurea, Euphorbia, among others), this pattern might reflect a higher number of studies performed by scholars using plants primarily 


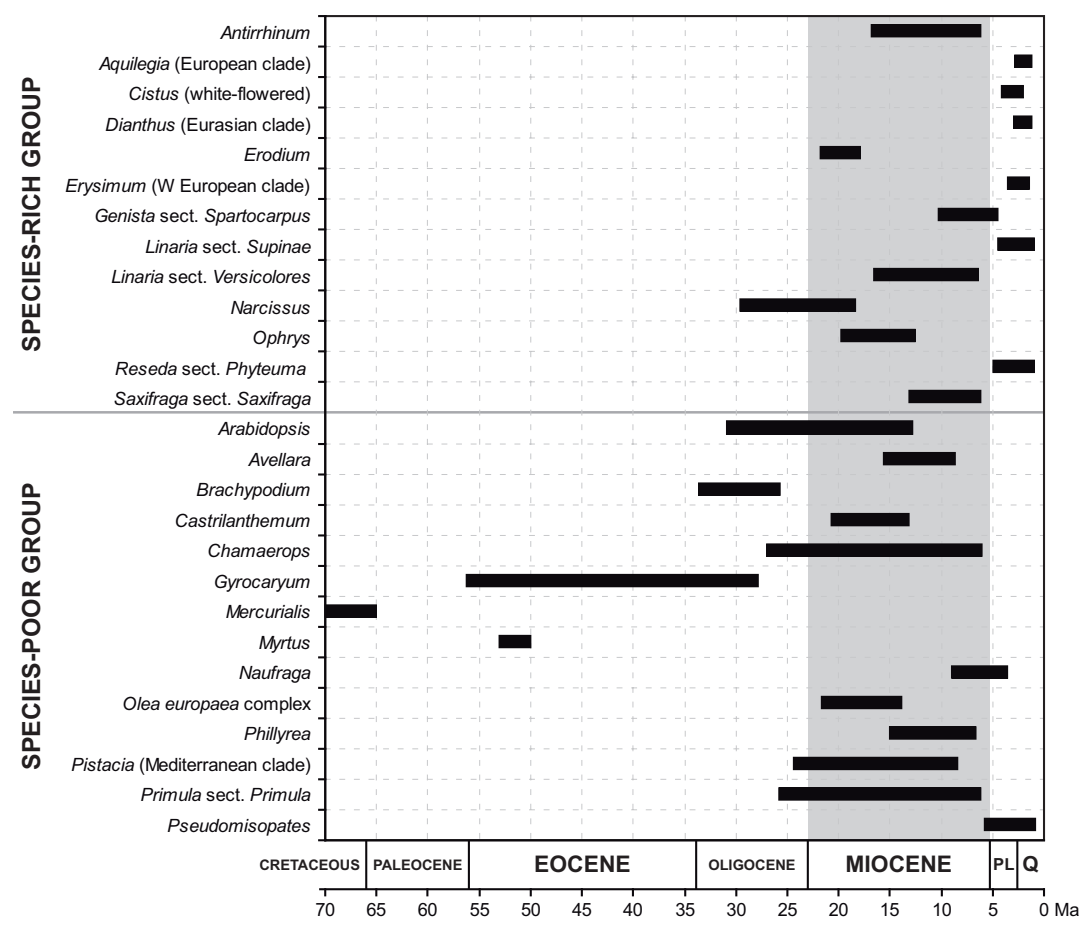

Fig. 4. Overview of times of divergence for Mediterranean clades and their sister groups (stem ages) based on previously published original estimates. The 27 clades categorised into a species-rich group (13 clades) and a species-poor group (14 species) are indicated (see Table S1). Bars represent uncertainty in divergence time estimates (in most cases, the 95\% highest posterior density intervals from Bayesian dating analyses). distributed in the western Mediterranean (see Table S1). Another, more general pattern is that many species of most plant clades show a strong geographical pattern of narrow endemicity. In addition to species endemic to islands, many species of those genera are endemic to mountains and small continental areas (capes, coastal stretches).

\section{Reproductive versus vegetative taxonomic characters}

The 27 Mediterranean plant clades analysed in this study (Table S2) show some predominant characteristics: (i) Habit, 20 herbs, five trees and two shrubs; (ii) Fruit type, 22 clades with dry fruits (12 capsules with numerous seeds) and five with fleshy fruits; (iii) Self-compatibility, 12 predominantly self-incompatible and 11 predominantly self-compatible; (iv) Flower sexual system, 24 with hermaphroditic flowers and five with alternative sexual expressions; (v) Fused petals, 12 gamopetalous, 12 choripetalous and three with no or only minute corolla; (vi) Flower shape, 15 open, eight tube-like and four alternative to these two types; (vii) Length of the floral unit (flower or particular inflorescences such as capitula), ten clades $>10 \mathrm{~mm}, 10$ clades $<10 \mathrm{~mm}$ and seven clades with both states; (viii) Pollination vectors, 13 insect generalists or semi-generalists, seven predominantly bees, six wind and one ants. Generalist pollinators were found in clades with a majority of generalist plant species, together with some other genera with species showing diverse insect specialisation.

We failed to find a clear pattern of particular plant traits strongly associated with plant diversity. Nevertheless, some sets of traits appear to be more common in one or the other group, such as herbs with dry fruits and a hermaphrodite sexual system in the species-rich clades, while small flowers and wind pollination was observed in six of the 14 speciespoor genera (Table S2). The only five plant clades of species bearing fleshy fruits were woody plants of the species-poor group.

The 27 plant clades show species with some traits associated with flower variation in shape and size that were too variable to be analysed (Table S2). Genetic self-compatibility is considered a trait at the species level, although numerous cases show some degree of leakage at the individual level within populations. Colouration patterns were not analysed in this study because of the high variability of this character among clades of numerous species. Indeed, flower colouration is not only variable among species but also within populations, which prevented us from including this character in the analysis. Nevertheless, colouration has been taxonomically used to some degree in Antirrhinum, Aquilegia, Cistus, Erysimum, Linaria, Narcissus, Ophrys and Primula.

Both vegetative and reproductive characters are extensively used in the taxonomy of the genera of the species-rich group. Overall, reproductive taxonomic characters are more commonly used for the recognition of European species than vegetative taxonomic characters (GLMM: AIC: 286.74, deviance $\left.=280.74, \mathrm{Chi}^{2}=6.75, \mathrm{df}=3, P<0.001\right)$. This pattern is supported by a high relevance of reproductive taxonomic characters in Erysimum, Linaria sect. Versicolores, Narcissus and Ophrys $(\mathrm{G}>6.7, \mathrm{df}=1, P<0.010)$, and to a lesser degree in Aquilegia, Genista and Reseda ( $\mathrm{G}>3.6, \mathrm{df}=1$, $P<0.056$ ) (Table 1$)$. In contrast, vegetative taxonomic characters significantly outnumbered reproductive characters only in Saxifraga $(\mathrm{G}=17.1, \mathrm{df}=1, P<0.001)$. No significant differences were observed in the number of vegetative and reproductive taxonomic characters in Antirrhinum, Cistus, Dianthus and Erodium $(\mathrm{G}<2.4, \mathrm{df}=1, P>0.124)$. Plant clades with bee or generalist pollination did not differ significantly in the relative importance of reproductive and vegetative characters for species recognition (GLM: AIC: 40.36, deviance $=0.049, \quad \mathrm{~F}=1.34, \mathrm{df}=11, \quad P=0.721 ; \quad$ Fig. 5$)$. The 


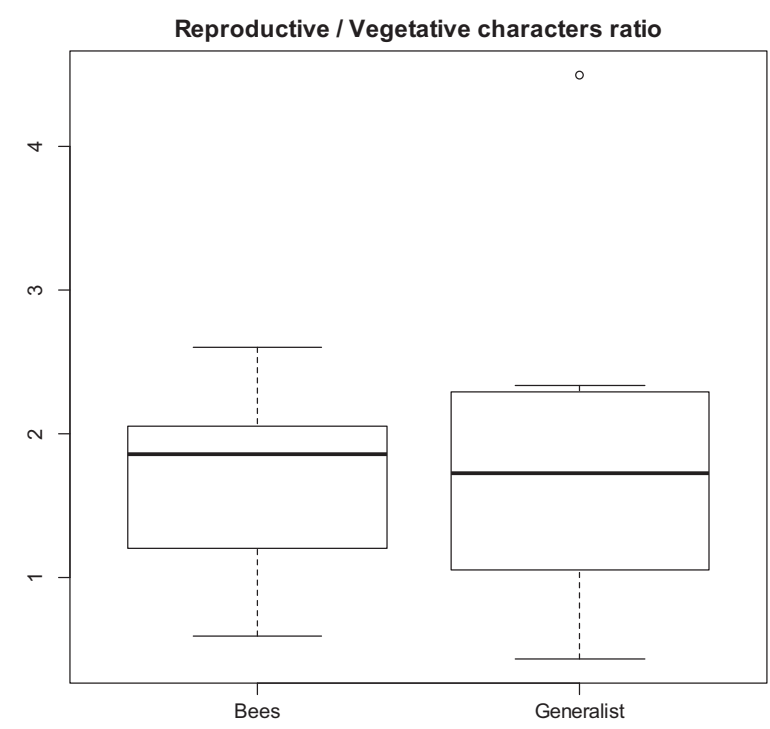

Fig. 5. Ratio between the number of reproductive and vegetative characters used for species recognition in taxonomy does not differ significantly between plant clades with pollination primarily dependent on generalist insects or bees. Data were taken from taxonomic data for species of 12 clades, which include all clades from the species-rich group (see Table 1) except for Ophrys (see Methods)

Ophrys clade was removed from this analysis, as it constitutes a clear outlier due to the relative importance of reproductive characters (49 of 50) that compromise the normality of the residuals; nevertheless, its exclusion did not affect the significance of the model.

\section{DISCUSSION}

Our results challenge the widely held notion that the onset of the Mediterranean climate (c. 3.2 Ma) and concomitant differentiation of Mediterranean plants took place since the Pliocene-Quaternary (3.2 Ma; Suc 1984). Based on chronological relationships of Pliocene-Quaternary pollen and foraminifera from the Mediterranean Basin, the establishment of the Mediterranean climate was additionally proposed by Suc (1984) to have occurred shortly after (2.8 Ma). However, the present review supports that divergence of Mediterranean clades and their sister groups primarily occurred in the Miocene or earlier.

\section{Miocene origin of Mediterranean clades}

Our review of the 27 time-calibrated phylogenies not only supports an estimated origin involving the Miocene for 16 clades, but also a pre-Miocene origin for another four clades (Fig. 4). This general result entails that the majority of lineages with Mediterranean species have an origin estimated sometime in the Miocene or earlier. Palaeobotanical evidence also points to a Miocene origin of xerophytic Mediterranean vegetation (Barrón et al. 2010). Fluvial and steppe-land woods appear to have dominated the Iberian Peninsula already in the UpperMiddle Miocene (Rivas-Carballo et al. 1994). This result suggests that a pre-Mediterranean syndrome needs to be revisited not only for the woody flora (Herrera 1992; Verdú et al. 2003) but also for herbs.
The 27 time-calibrated phylogenies also show that low speciation despite ancient origin (evolutionary stasis) is not exclusively related to a particular ancient period inasmuch as clades containing a single Mediterranean species (species-poor clades) appear to have diverged in different geological periods: the Eocene (Myrtus), Eocene-Oligocene (Gyrocaryum), OligoceneMiocene (Chamaerops), Miocene (Avellara, Castrilanthemum, Olea) and Miocene-Pliocene (Naufraga). This result is partially in agreement with long-term survival of old lineages as supported by plant traits (Verdú et al. 2003) that are different to the characters used in this study. In contrast to species-poor clades, a more recent origin was primarily inferred for the species-rich clades: Oligocene-Miocene (Narcissus), Miocene (Antirrhinum, Erodium, Linaria sect. Versicolores, Ophrys, Saxifraga) and Pliocene-Quaternary (Aquilegia, white-flowered Cistus, Eurasian Dianthus, western Erysimum, Linaria sect. Supinae; see also Fiz \& Valcárcel 2013). This result does not support the hypothesis of ancient divergence of species-rich clades, and thus long time for accumulation of species (Darwin 1859; Valente \& Vargas 2013). Some species-rich clades not only show a Quaternary divergence pattern but also explosive radiations - i.e. generation of large numbers of species and lineages in a short period of time - in the MFR. Indeed, Mediterranean plants offer very clear examples of explosive radiations on Earth (e.g. in Cistus, Guzmán et al. 2009; Dianthus, Valente et al. 2010; Erysimum, Moazzeni et al. 2014).

Based on all these results and palaeobotanical data, we hypothesise that numerous plant clades originated in the Miocene, when some xeric areas were scattered across the Mediterranean Basin. Indeed, the flora of Mediterranean Europe appears to have originated as an assemblage of clades of different origins, as already proposed for some other Mediterraneantype ecosystems (Wen \& Ickert-Bond 2009; Kadereit \& Baldwin 2012; Rundel et al. 2016; but see exceptions in Vargas et al. 2014). The establishment of a Mediterranean climate appears to have happened in post-Miocene times (Suc 1984), and thus an extensive region provided a large number of opportunities for plant colonisation and speciation in mountains, peninsulas and islands in the Quaternary, generating the diversity of the speciose groups observed today (Rundel et al. 2016).

\section{Geographical speciation and floral traits}

The species of the 27 plant clades of the present study show a strong pattern of geographical speciation (Table S1). Unique opportunities for spatial isolation of lineages in the Mediterranean realm were provided by the complex geography and orography of southern Europe since the Paleocene (Rosenbaum et al. 2002; Rundel et al. 2016). As a result, isolation followed by speciation in restricted areas brought about narrow endemics to Mediterranean islands (Fernández-Mazuecos et al. 2014), mountains (Jiménez-Mejías et al. 2015, 2017) and even coastal plains (Fernández-Mazuecos et al. 2016). Geographical isolation together with climatic changes dramatically fluctuating in the Mediterranean Basin during the Quaternary may account for a high number of refugia not only in the three European peninsulas (Balkans, Italy, Iberia) but also in small pockets of climatically stable areas (Hewitt 2000). Indeed, 52 putative refugia have been proposed across the Mediterranean Basin, most of them in the western MFR (Médail \& Diadema 2009). 
Vegetative and reproductive traits are used to recognise species of any flora. In particular, vegetative characters (life cycle, size, leaf shape, indumentum, among others) provide key characters used in the taxonomy of European plants (Tutin et al. 1964-1980). The same is true for reproductive characters that additionally have been claimed many times as linked to pollinators and speciose clades (see references in Table S2). We found a preponderance of reproductive characters in most clades of the species-rich group that as a whole are probably linked to speciation. However, a combination of these two types of key characters has been needed for taxonomists to circumscribe populations into species (Table 1). This is particularly true for Antirrhinum, Cistus, Dianthus and Erodium, which show a similar number of vegetative and reproductive taxonomic characters. Morphological variation of vegetative parts (typically leaf shape and indumentum) was more important than reproductive parts to discriminate species in one case (Saxifraga). Species delimitation has primarily been based on floral characters in eight genera, and thus potentially linked to pollinators (Reseda, Martín-Bravo et al. 2007; Aquilegia, Bastida et al. 2010; Narcissus, Santos-Gally et al. 2012; Linaria sect. Versicolores, Fernández-Mazuecos et al. 2013; Erysimum, Moazzeni et al. 2014; Genista, De Castro et al. 2015; Linaria sect. Supinae, Blanco-Pastor et al. 2015; Ophrys, Breitkopf et al. 2015). Nevertheless, we did not find any statistical support that associates speciose clades with specialist (bees) or generalist pollination when the 13 (or 12, excluding Ophrys) species-rich clades are taken together (Fig. 5).

\section{CONCLUSIONS}

Mediterranean plant clades appear to have had an earlier origin than considered in the last decades. Our hypothesis of some small, xeric areas scattered across the Mediterranean Basin during the Tertiary that became large, xeric areas in the Quaternary is compatible with previous palaeobotanical results (Suc 1984; Barrón et al. 2010). We envision an evolutionary process in which lineages adapted to pre-Mediterranean conditions were strongly competitive when the Mediterranean climate became dominant in southern Europe and northern Africa.
Although the scheme proposed by Darwin (1859) for phylogenetic diversity provides a useful framework to infer evolutionary processes in large territories such as the Mediterranean Basin, we failed to support his strongly held notion that natura non facit saltum (Friedman 2009). Irrespective of time of origin for Mediterranean clades, the body of knowledge accumulated since Darwin's research leads us to consider a predominant pattern of geographical isolation in the Mediterranean Basin as a main evolutionary driver. Ecological divergence caused by orography, soils and pollinators in concert additionally operated particularly in some species-rich genera (Thompson 2005).

\section{ACKNOWLEDGEMENTS}

We are grateful to those who published data and results used in this review, as well as botanical experts who were consulted: Juan José Aldasoro (Geraniaceae), Pilar Catalán (Brachypodium), Elena Conti (Primula), Marcial Escudero (Carex), José María Gómez (Erysimum), Modesto Luceño (Cyperaceae), Santiago Martín-Bravo (Reseda), Ana Otero (Gyrocaryum), Andrew Thornhill (Myrtaceae) and Luis Valente (Dianthus). The Conselleria de Medio Ambiente del Gobierno Balear gave permit for the reproduction of photograph $\mathrm{G}$ of Figure 2. R.H. was funded by the Fundação para Ciência e Tecnologia (IF/00441/2013) and by the Marie Curie Action (FP7-PEOPLE-2012-CIG-321794), M.F.-M. was funded by a Juan de la Cierva fellowship (IJCI2015-23459) and P.V. was funded by the Spanish Ministry of Economy and Competitiveness (CGL2012-38624-C02-01).

\section{SUPPORTING INFORMATION}

Additional Supporting Information may be found online in the supporting information tab for this article:

Table S1. Evolutionary patterns of species-rich and speciespoor plant clades of the Mediterranean region.

Table S2. Traits of plants (typically genera) from the species-rich and species-poor groups.

Appendix S1. References for Table S1 and Table S2.

\section{REFERENCES}

Barrón E., Rivas-Carballo R., Postigo-Mijarra J.M., Alcalde-Olivares C., Vieira M., Castro L., Pais J., Valle-Hernández M. (2010) The Cenozoic vegetation of the Iberian Peninsula: a synthesis. Review of Palaeobotany and Palynology, 162, 382-402.

Bastida J., Alcántara J.M., Rey P.J., Vargas P., Herrera C.M. (2010) Extended phylogeny of Aquilegia: the biogeographical and ecological patterns of two simultaneous but contrasting radiations. Plant Systematics and Evolution, 28, 171-185.

Blanco-Pastor J.L., Ornosa C., Romero D., Liberal I., Gómez J.M., Vargas P. (2015) Bee morphotypes explain floral variation in a radiation of Linaria species. Journal of Evolutionary Biology, 28, 851863.

Breitkopf H., Onstein R.E., Cafasso D., Schlüter P.M., Cozzolino S. (2015) Multiple shifts to different pollinators fuelled rapid diversification in sexually deceptive Ophrys orchids. New Phytologist, 207, 377-389.
Darwin C. (1859) On the origin of species by means of natural selection, or the preservation of favoured races in the struggle for life. John Murray, London, UK, p 502.

De Castro O., Véla E., Vendramin G.G., Gargiulo R. Caputo P. (2015) Genetic structure in the Genista ephedroides complex (Fabaceae) and implications for its present distribution. Botanical Journal of the Linnean Society, 177, 607-618.

Donoghue M.J., Bell C.D., Li J. (2001) Phylogenetic patterns in Northern Hemisphere plant geography. International Journal of Plant Science, 162, S41S52.

Euro+Med PlantBase (2006). Euro+Med PlantBase the information resource for Euro-Mediterranean Plant Diversity, Berlin, Germany. Availabe from www.emplantbase.org/home.html (accessed July, 2017).

Faegri K., van der Pijl L. (1979) The Principles of Pollination Ecology. Pergamon, London, UK, p 244.

Fernández-Mazuecos M., Blanco-Pastor J.L., Gómez J.M., Vargas P. (2013) Corolla morphology influences diversification rates in bifid toadflaxes (Linaria sect. Versicolores). Annals of Botany, 112, 1705-1722.

Fernández-Mazuecos M., Jiménez-Mejías P., RotllanPuig X., Vargas P. (2014) Narrow endemics to Mediterranean islands: moderate genetic diversity but narrow climatic niche of the ancient, critically endangered Naufraga (Apiaceae). Perspectives in Plant Ecology, Evolution and Systematics, 16, 190-202.

Fernández-Mazuecos M., Jiménez-Mejías P., MartínBravo S., Buide M.L., Álvarez I., Vargas P. (2016) Narrow endemics on coastal plains: Miocene divergence of the critically endangered genus Avellara (Compositae). Plant Biology, 18, 729-738.

Fiz O., Valcárcel V. (2013) From Messinian crisis to Mediterranean climate: a temporal gap of diversification recovered from multiple plant phylogenies. Perspectives in Plant Ecology, Evolution and Systematics, 15, 130-137.

Forest F., Grenyer R., Rouget M., Davies T.J., Cowling R.M., Faith D.P., Balmford A., Manning J.C., Proche S., van der Bank M., Reeves G., Hedderson T.A.J., 
Savolainen V. (2007) Preserving the evolutionary potential of floras in biodiversity hotspots. Nature, 445, 757-760.

Friedman W.E. (2009) The meaning of Darwin's "abominable mystery”. American Journal of Botany, 96, 5-21.

Guzmán B., Lledo M.D., Vargas P. (2009) Adaptive Radiation in Mediterranean Cistus (Cistaceae). PLoS ONE, 4, e6362.

Harmon L.J., Weir J.T., Brock C.D., Glor R.E., Challenger W. (2008) GEIGER: investigating evolutionary radiations. Bioinformatics, 24, 129-131.

Herrera C.M. (1992) Historical effects and sorting processes as explanations for contemporary ecological patterns: character syndromes in Mediterranean woody plants. The American Naturalist, 140, 421-446.

Hewitt G.M. (2000) The genetic legacy of the Quaternary ice ages. Nature, 405, 907-913.

Jiménez-Mejías P., Fernández-Mazuecos M., Amat M.E., Vargas P. (2015) Narrow endemics in European mountains: high genetic diversity within the monospecific genus Pseudomisopates (Plantaginaceae) despite isolation since the late Pleistocene. Journal of Biogeography, 42, 1455-1468.

Jiménez-Mejías P., Fernández-Mazuecos M., Gutiérrez L., Álvarez I., Vargas P. (2017) Narrow endemics in Mediterranean scrublands: high gene flow buffers genetic impoverishment in the annual monospecific Castrilanthemum (Asteraceae). Biodiversity and Conservation, In press. https://doi.org/10.1007/s10531017-1374-0.

Kadereit J., Baldwin B. (2012) Western Eurasianwestern North American disjunct plant taxa: the dry-adapted ends of formerly widespread north temperate mesic lineages - and examples of longdistance dispersal. Taxon, 61, 3-17.

Mabberley D.J. (1997) The plant-book: a portable dictionary of the vascular plants. Cambridge University Press, Cambridge, UK, p 858.

Magallón S., Sanderson M.J. (2001) Absolute diversification rates in angiosperm clades. Evolution, 55, 1762-1780.

Martín-Bravo S., Meimberg H., Luceño M., Märkl W., Valcárcel V., Bräuchler C., Vargas P., Heubl G. (2007) Molecular systematics and biogeography of Resedaceae based on ITS and trnL-F sequences. Molecular Phylogenetics and Evolution, 44, 1105-1120.

Médail F., Diadema K. (2009) Glacial refugia influence plant diversity patterns in the Mediterranean basin. Journal of Biogeography, 36, 1333-1345.
Mishler B.D., Knerr N., González-Orozco C.E., Thornhill A.H., Laffan S.W., Miller J.T. (2014) Phylogenetic measures of biodiversity and neo- and paleo-endemism in Australian Acacia. Nature Communications, 5, 4473.

Mittermeier R.A., Gil R.R., Hoffman M., Pilgrim J., Brooks T., Mittermeier C.G., Lamoreux J., da Fonseca G.A.B. (2004). Hotspots revisited: Earth's biologically richest and most threatened terrestrial ecoregions. CEMEX, Mexico D.F., Mexico: 390 pp.

Moazzeni H., Zarre S., Pfeil B.E., Bertrand Y.J.K., German D.A., Al-Shehbaz I.A., Mummenhoff K., Oxelman B. (2014) Phylogenetic perspectives on diversification and character evolution in the species-rich genus Erysimum (Erysimeae; Brassicaceae) based on a densely sampled ITS approach. Botanical Journal of the Linnean Society, 175, 497-522.

R Development Core Team. (2015) R: a language and environment for statistical computing. R Foundation for Statistical Computing, Vienna, Austria.

Rivas-Carballo M.R., Alonso-Gavilán G., Valle M.F., Civis J. (1994) Miocene palynology of the central sector of the Duero basin (Spain) in relation to palaeogeography and palaeoenvironment. Review of Palaeobotany and Palynology, 82, 251-264.

Ronquist F. (2014) Systematics, charting the tree of life. In: Vargas P., Zardoya R. (Eds), The Tree of Life: Evolution and Classification of Living Organisms. Sinauer Associates, Sunderland, MA, USA, pp $1-11$.

Rosenbaum G., Lister G.S., Duboz C. (2002) Reconstruction of the tectonic evolution of the western Mediterranean since the Oligocene. Journal of Virtual Explorer, 8, 107-130.

Rundel P.W., Arroyo M.T.K., Cowling R.M., Keeley J.E., Lamont B.B., Vargas P. (2016) Mediterranean biomes: evolution of their vegetation, floras, and climate. Annual Review of Ecology, Evolution, and Systematics, 47, 383-407.

Rutschmann F. (2006) Molecular dating of phylogenetic trees: a brief review of current methods that estimate divergence times. Diversity and Distributions, 12, 35-48.

Santos-Gally R., Vargas P., Arroyo J. (2012) Insights into Neogene Mediterranean biogeography based on phylogenetic relationships of mountain and lowland lineages of Narcissus (Amaryllidaceae). Journal of Biogeography, 39, 782-798.
Stuessy T. (2008) Plant Taxonomy: The Systematic Evaluation of Comparative Data. Columbia University Press, New York, USA, p 568.

Suc J.P. (1984) Origin and evolution of the mediterranean vegetation and climate in Europe. Nature, 307, 429-432.

Thompson J.D. (2005) Plant Evolution in the Mediterranean. Oxford University Press, Oxford, UK, p 293.

Tutin T.G., Heywood V.H., Burges N.A., Moore D.M., Valentine D.H., Walters S.M., Webb D.A (19641980) Flora Europaea (vols 1-5), Cambridge University Press, Cambridge, UK.

Valente L.M., Vargas P. (2013) Contrasting evolutionary hypotheses between two mediterranean-climate floristic hotspots: the cape of southern Africa and the Mediterranean basin. Journal of Biogeography, 40, 2032-2046.

Valente L.M., Savolainen V., Vargas P. (2010) Unparalleled rates of species diversification in Europe. Proceedings of the Royal Society of London series B, 277, 1489-1496.

Vargas P. (2007) Are Macaronesian islands refugia of relict plant lineages?: a molecular survey. In: Weiss S. J., Ferrand N. (Eds), Phylogeography in southern European refugia: evolutionary perspectives on the origins and conservation of European biodiversity. Springer, Berlin, Germany, pp 297-314.

Vargas P., Zardoya R. (2014) The Tree of Life: Evolution and Classification of Living Organisms. Sinauer Associates, Sunderland, MA, USA, p 713.

Vargas P., Valente L.M., Blanco-Pastor J.L., Liberal I., Guzmán B., Cano E., Forrest A., Fernández-Mazuecos M. (2014) Testing the biogeographical congruence of palaeofloras using molecular phylogenetics: snapdragons and the Madrean-Tethyan flora. Journal Biogeography, 41, 932-943.

Verdú M., Dávila P., García-Fayos P., Flores-hernández N., Valiente-Banuet A. (2003) 'Convergent' traits of mediterranean woody plants belong to pre-mediterranean lineages. Biological Journal of the Linnean Society, 78, 415-427.

Wen J., Ickert-Bond S.M. (2009) Evolution of the Madrean-Tethyan disjunctions and the North and South American amphitropical disjunctions in plants. Journal of Systematics and Evolution, 47, 331348.

Winston J.E. (1999) Describing Species: Practical Taxonomic Procedure for Biologists. Columbia University Press, New York, USA, p 519. 